\title{
Comamonas odontotermitis sp. nov., isolated from the gut of the termite Odontotermes formosanus
}

Correspondence
Wen-Ming Chen
p62365@ms28.hinet.net

\author{
Jui-Hsing Chou, ${ }^{1}$ Shih-Yi Sheu, ${ }^{2}$ Kuan-Yin Lin, ${ }^{3}$ Wen-Ming Chen, ${ }^{3}$ \\ A. B. Arun ${ }^{1}$ and Chiu-Chung Young ${ }^{1}$ \\ ${ }^{1}$ Department of Soil Environmental Science, College of Agriculture and Natural Resources, \\ National Chung Hsing University, Taichung, Taiwan \\ ${ }^{2}$ Department of Marine Biotechnology, National Kaohsiung Marine University, Kaohsiung, \\ Taiwan \\ ${ }^{3}$ Laboratory of Microbiology, Department of Seafood Science, National Kaohsiung Marine \\ University, 142 Hai-Chuan Road, Nan-Tzu, Kaohsiung City 811, Taiwan
}

\begin{abstract}
A bacterial strain, designated Dant 3-8 ${ }^{\top}$, isolated from the gut of the termite Odontotermes formosanus, was investigated by a polyphasic taxonomic approach. The cells were rod-shaped, Gram-negative, non-pigmented, non-spore-forming and non-fermentative. Phylogenetic analyses using the 16S rRNA gene sequence showed that the strain formed a monophyletic branch towards the periphery of the evolutionary radiation occupied by the genus Comamonas, its closest neighbours being Comamonas testosteroni DSM $50244^{\top}$ ( $96.4 \%$ sequence similarity), Comamonas koreensis KCTC $12005^{\top}(96.0 \%)$ and Comamonas terrigena DSM 7099 ${ }^{\top}(96.2 \%)$. Strain Dant 3-8 ${ }^{\top}$ was clearly distinguished from all of these strains by using phylogenetic analysis, DNA-DNA hybridization, whole-cell protein profiles, fatty acid composition data and a range of physiological and biochemical characteristics. It is evident from the genotypic and phenotypic data that Dant $3-8^{\top}$ represents a novel species in the genus Comamonas, for which the name Comamonas odontotermitis sp. nov. is proposed. The type strain is Dant $3-8^{\top}(=\mathrm{BCRC}$ $17576^{\top}=$ LMG $23579^{\top}$ ).
\end{abstract}

The genus Comamonas, proposed by De Vos et al. (1985), belongs to family Comamonadaceae of the class Betaproteobacteria. At the time of writing, the genus encompasses eight recognized species: Comamonas terrigena, C. aquatica, $C$. badia, C. denitrificans, C. kerstersii, C. koreensis, C. nitrativorans and $C$. testosteroni. The aim of the present study was to determine the taxonomic position of strain Dant $3-8^{\mathrm{T}}$, isolated from the gut of the termite Odontotermes formosanus (Shiraki).

Strain Dant $3-8^{\mathrm{T}}$ was isolated from the gut of termites collected from a decayed bamboo tree located in Pingtung County in southern Taiwan. For this purpose, termites were surface-sterilized with $75 \%$ ethanol for $10 \mathrm{~s}$ and with $0.1 \%$ $(\mathrm{w} / \mathrm{v})$ mercuric chloride for $10 \mathrm{~min}$, rinsed several times in sterile distilled water, crushed and streaked on desoxycholate agar plates (BD Difco) and incubated at $25^{\circ} \mathrm{C}$. The strain was further maintained and subcultivated on nutrient agar (BD Difco) at $25^{\circ} \mathrm{C}$. Type strains of C. badia,

The GenBank/EMBL/DDBJ accession number for the 16S rRNA gene sequence of strain Dant $3-8^{\top}$ is DQ453128.

Whole-cell protein profiles of strain Dant $3-8^{\top}$ and related strains are available as supplementary material in IJSEM Online.
C. denitrificans, C. koreensis, C. nitrativorans and C. testosteroni were obtained from the Deutsche Sammlung von Mikroorganismen und Zellkulturen GmbH (DSMZ) and type strains of C. aquatica, C. kerstersii and C. terrigena were obtained from the Laboratorium voor Microbiologie Bacteriënverzameling (LMG) for comparison.

Cultural and morphological characteristics were observed on nutrient agar. Cell morphology was observed under a light microscope. The motility of cells was tested by the hanging drop method. The Gram stain kit-S (BD Difco) was used for Gram staining. The optimum $\mathrm{pH}$ range for growth was examined by measuring the $\mathrm{OD}_{595}$ of cultures grown in tryptic soy broth (BD Difco) and nutrient broth adjusted to various $\mathrm{pH}$ values ( $\mathrm{pH} 4-10$ at intervals of $0.5 \mathrm{pH}$ units) using appropriate biological buffers (Chung et al., 1995). Tolerance of the strain to various levels of $\mathrm{NaCl}$ was tested in nutrient broth, which was adjusted to different $\mathrm{NaCl}$ concentrations (w/v; $0,0.5 \%$ and $1.0-5.0 \%$ at intervals of $1.0 \%)$. The optimum temperature for growth was examined in tryptic soy broth and nutrient broth adjusted to $\mathrm{pH} 7$. Growth was examined by measuring the $\mathrm{OD}_{595}$ of cultures grown at various temperatures $\left(4-45^{\circ} \mathrm{C}\right)$. Growth under anaerobic conditions was determined after incubating the strains in the Oxoid AnaeroGen system. 
Cells of strain Dant $3-8^{\mathrm{T}}$ were Gram-negative, motile, nonspore-forming rods, $0.5-1.0 \mu \mathrm{m}$ in diameter and 2.0 $2.5 \mu \mathrm{m}$ long. No accumulation of poly- $\beta$-hydroxybutyrate granules as inclusion bodies was observed. Strain Dant $3-8^{\mathrm{T}}$ formed visible circular colonies with an umbonate elevation, semi-transparent with irregular edges. The colony diameter was approximately $1.5-3.0 \mathrm{~mm}$ on nutrient agar after $48 \mathrm{~h}$ of incubation at $25^{\circ} \mathrm{C}$. Strain Dant $3-8^{\mathrm{T}}$ grew well at $15-$ $37^{\circ} \mathrm{C}, 0-2 \% \mathrm{NaCl}$ and $\mathrm{pH} 6-9$. Optimum growth was observed at $28-35^{\circ} \mathrm{C}, 0-1 \% \mathrm{NaCl}$ and $\mathrm{pH}$ 7.0. Strain Dant $3-8^{\mathrm{T}}$ was unable to grow at $25^{\circ} \mathrm{C}$ after $120 \mathrm{~h}$ of incubation under anaerobic conditions.

Extraction of chromosomal DNA, PCR amplification and sequencing of the $16 \mathrm{~S}$ rRNA gene was carried out as described previously (Chen et al., 2001). Sequence analysis was achieved using a DNA sequencer (ABI PRISM 310 instrument; Applied Biosystems) and sequences were assembled by using the Fragment Assembly System program from the Wisconsin package 9.1. The resultant sequence was compared with available 16S rRNA gene sequences from the RDP and GenBank databases. Multiple-sequence alignment including strain Dant $3-8^{\mathrm{T}}$ and its closest relatives was performed using BioEdit software (Hall, 1999). Phylogenetic trees were inferred using the maximum-parsimony (Kluge \& Farris, 1969) and neighbour-joining (Saitou \& Nei, 1987) tree-making algorithms. An evolutionary distance matrix was generated for the neighbour-joining algorithm using the Jukes \& Cantor (1969) distance model and bootstrap analysis (1000 resamplings).

A nearly complete $16 \mathrm{~S}$ rRNA gene sequence (1453 bp) was obtained for strain Dant $3-8^{\mathrm{T}}$. A comparison of the sequence with those of representatives of genera classified in the family Comamonadaceae of the class Betaproteobacteria showed that the organism fell within the evolutionary radiation occupied by the genus Comamonas (Fig. 1). According to sequence similarity calculations, the organism was most closely related to C. testosteroni DSM $50244^{\mathrm{T}}$ (96.4\% similarity), C. koreensis KCTC $12005^{\mathrm{T}}$ (96.0\%), C. terrigena DSM $7099^{\mathrm{T}}(96.2 \%)$, C. kerstersii LMG $3475^{\mathrm{T}}$ (95.9\%), C. nitrativorans $23310^{\mathrm{T}}(95.4 \%)$, C. aquatica $\mathrm{LMG}$ $2370^{\mathrm{T}}(95.3 \%)$, C. denitrificans $123^{\mathrm{T}}(95.0 \%)$ and C. badia IAM $14839^{\mathrm{T}}(93.1 \%)$. The $16 \mathrm{~S}$ rRNA gene sequence similarity of strain Dant $3-8^{\mathrm{T}}$ with other species within the class Betaproteobacteria was less than $95 \%$.

Whole genome DNA-DNA hybridization experiments were performed with photobiotin-labelled probes as described by Ezaki et al. (1989). The degree of hybridization was calculated by means of triplicate experiments. The separate species status of strain Dant $3-8^{\mathrm{T}}$ was demonstrated by the hybridization values obtained when it was hybridized with C. terrigena LMG $5929^{\mathrm{T}}$, C. koreensis DSM $18232^{\mathrm{T}}$ and C. testosteroni DSM $50244^{\mathrm{T}}$, which respectively showed $56.0 \pm 3.3,40.2 \pm 5.4$ and $14.5 \pm 3.5 \%$ DNA-DNA relatedness. The DNA-DNA relatedness between strain Dant $3-8^{\mathrm{T}}$ and its closest phylogenetic neighbours was well below the $70 \%$ cut-off point recommended for the assignment of strains to the same genomic species (Wayne et al., 1987). Based on the above DNA-DNA relatedness data, isolate Dant $3-8^{\mathrm{T}}$ warrants separate species status in the genus Comamonas.

For $\mathrm{G}+\mathrm{C}$ content calculations, DNA samples were prepared in duplicate and degraded enzymically into nucleosides as described by Mesbah et al. (1989). The obtained nucleoside mixture was then separated by HPLC. The DNA G+C content of strain Dant $3-8^{\mathrm{T}}$ was $61.6 \mathrm{~mol} \%$ (individual measurements of 61.1 and $62.1 \mathrm{~mol} \%$ ).

Further differentiation of strain Dant $3-8^{\mathrm{T}}$ from its closest phylogenetic neighbours was examined by protein electrophoretic patterns and fatty acid profiling. Biomass for fatty acid studies was grown in nutrient medium for 2 days at $28^{\circ} \mathrm{C}$ as described by Chang et al. (2002) and Tago \& Yokota (2004). Fatty acid methyl esters were prepared, separated and identified according to the instructions of the Microbial Identification System (MIDI Inc.). Preparation of whole-cell proteins and SDS-PAGE were performed as described by Pot

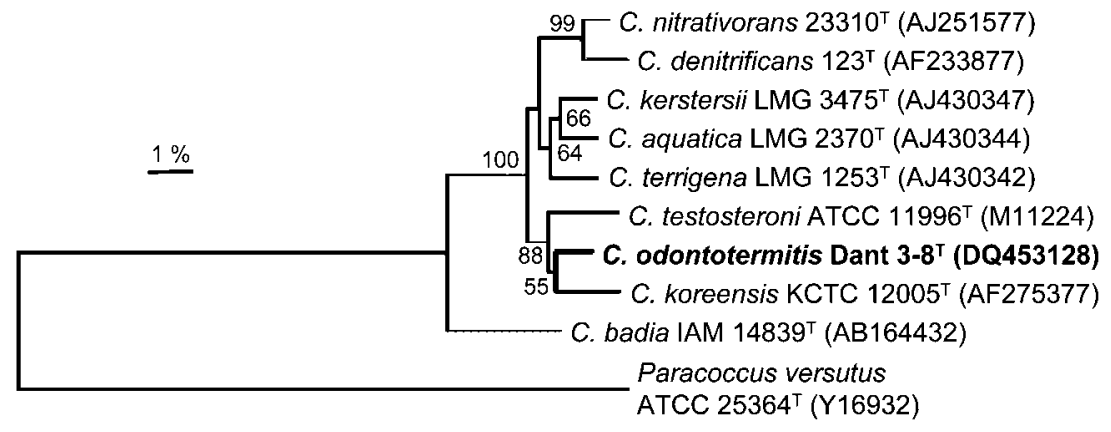

Fig. 1. Phylogenetic analysis based on $16 \mathrm{~S}$ rRNA gene sequences available from the EMBL database (accession numbers in parentheses) constructed after multiple alignments of data showing the position of strain Dant $3-8^{\top}$ in the genus Comamonas. Distances were calculated and clustering with the neighbour-joining method was performed by using the software package BioEdit. Numbers at nodes are percentage bootstrap values based on 1000 resampled datasets; only values above $50 \%$ are given. Bar, $1 \%$ sequence dissimilarity. 
et al. (1994). Electrophoretic protein patterns were recorded on a Umax Astra 1220 S scanner (Umax Systems) and analysed with the Universal Software 1D Advanced from Advanced American Biotechnology \& Imaging (Fullerton, CA, USA) for normalization of the protein profiles and numerical analysis using UPGMA. A simple band-matching method was used for clustering. Bands with migration distance differences of less than $3 \%$ were considered as the same. Correlation coefficients are expressed as percentage similarity.

Predominant fatty acids of strain Dant $3-8^{\mathrm{T}}$ were $16: 0$ $(33.6 \%), \quad 18: 1 \omega 7 c(16.2 \%)$ and summed feature 3 $(16: 1 \omega 7 c$ and/or $15: 0$ iso $2-\mathrm{OH} ; 33.9 \%)$. The fatty acid pattern of strain Dant $3-8^{\mathrm{T}}$ is shown in Table 1 in comparison with those of representative Comamonas species. Although strain Dant $3-8^{\mathrm{T}}$ showed a profile typical of Comamonas (Chang et al., 2002; Wauters et al., 2003; Tago \& Yokota, 2004), it could be clearly distinguished from the type strains of its closest phylogenetic neighbours $C$. koreensis, $C$. terrigena and $C$. testosteroni by the absence of $14: 0,15: 0$ and 17:0 (Table 1). The whole-cell protein profile of strain Dant $3-8^{\mathrm{T}}$ was comparable to those of the type strains of $C$. koreensis, C. testosteroni, C. terrigena and C. kerstersii within $87 \%$ similarity (Supplementary Fig. S1 available in IJSEM Online), but few band positions unique to Dant $3-8^{\mathrm{T}}$ could be identified. These results further warrant a separate position for strain Dant $3-8^{\mathrm{T}}$ within the genus Comamonas.

Strain Dant $3-8^{\mathrm{T}}$ was examined for a broad range of phenotypic properties. Additional biochemical tests were performed to assess the carbon source utilization pattern by the Biolog GN2 and API ZYM, API 20E and API 20NE (bioMérieux) microtest systems according to the methods outlined by the manufacturers. Sensitivity of strain Dant $3-8^{\mathrm{T}}$ to various antibiotics was examined by disc diffusion assays (Bauer et al., 1966). The antibiotic discs contained ampicillin $(10 \mu \mathrm{g})$, chloramphenicol $(30 \mu \mathrm{g})$, gentamicin $(10 \mu \mathrm{g})$, kanamycin $(30 \mu \mathrm{g})$, nalidixic acid $(30 \mu \mathrm{g})$, novobiocin $(30 \mu \mathrm{g})$, rifampicin $(5 \mu \mathrm{g})$, penicillin $\mathrm{G}(10 \mathrm{U})$, streptomycin $(10 \mu \mathrm{g})$ or tetracycline $(30 \mu \mathrm{g})$. The effect of antibiotics on cell growth was assessed after 3 days of incubation.

Detailed results of biochemical characterization and antibiotic sensitivity are provided in Table 2 and in the species description. It is evident from Table 2 that there are several phenotypic characters that readily separate strain Dant $3-8^{\mathrm{T}}$ from phylogenetically related species. Taking together the results of $16 \mathrm{~S}$ rRNA gene sequencing, DNA-DNA hybridization and chemotaxonomic analyses, it is evident that strain Dant $3-8^{\mathrm{T}}$ should be classified within a novel species in the genus Comamonas, for which the name Comamonas odontotermitis sp. nov. is proposed.

\section{Description of Comamonas odontotermitis sp. nov.}

Comamonas odontotermitis (o.don'to.ter'mi.tis. N.L. n. Odontotermes the scientific name of a genus of termite; N.L. gen. n. odontotermitis of a termite of the genus

Table 1. Comparison of the fatty acid composition of strain Dant $3-8^{\top}$ with those of other Comamonas species

Strains: 1, Dant 3-8 ${ }^{\mathrm{T}}$ (C. odontotermitis sp. nov.); 2, C. koreensis DSM $18232^{\mathrm{T}}$; 3, C. testosteroni DSM 50244 ${ }^{\mathrm{T}}$; 4, C. terrigena LMG $1253^{\mathrm{T}}$; 5 , C. denitrificans DSM $17887^{\mathrm{T}}$; 6, C. nitrativorans DSM $13191^{\mathrm{T}}$; 7, C. aquatica LMG $2370^{\mathrm{T}}$; 8, C. kerstersii LMG $3475^{\mathrm{T}}$; 9 , C. badia DSM $17552^{\mathrm{T}}$. Data in columns 2-4 and 9 were obtained from Chang et al. (2002) and Tago \& Yokota (2004). Values are percentages of total fatty acids; -, fatty acids representing less than $0.5 \%$.

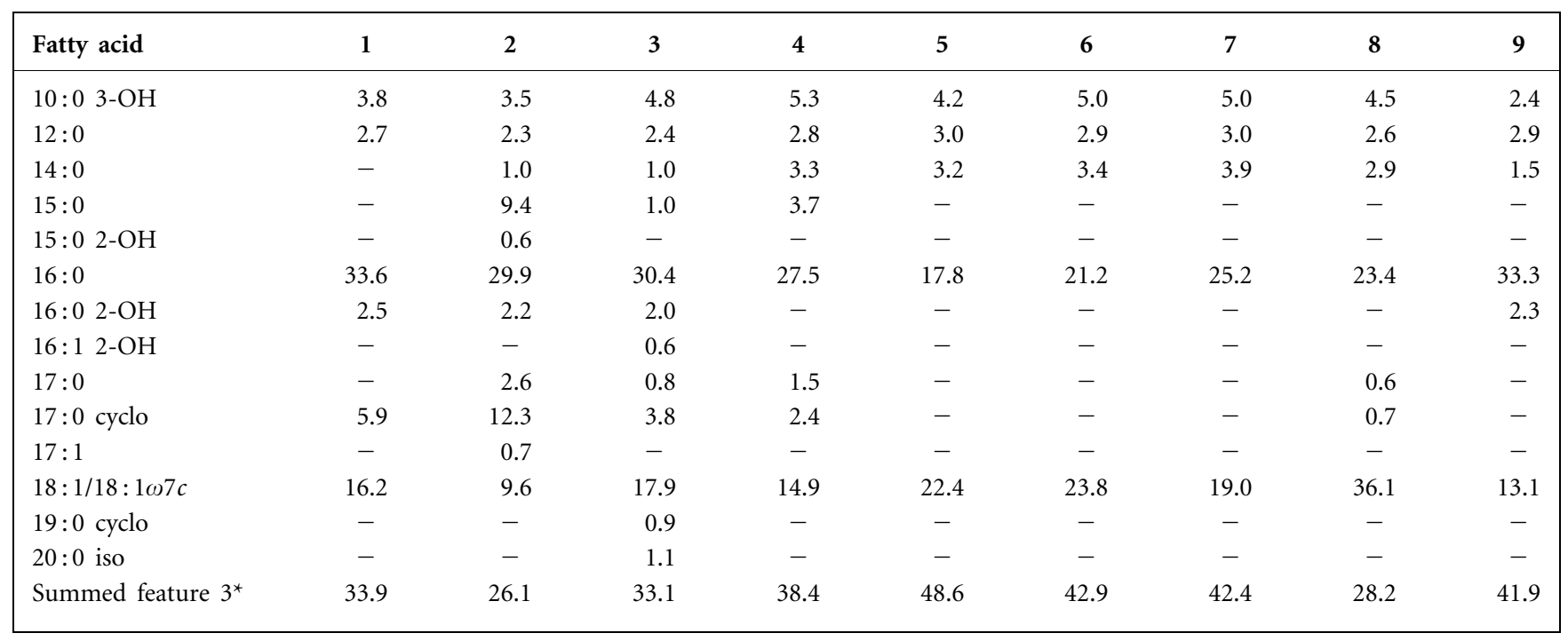

${ }^{*}$ Summed feature 3 comprises $16: 1 \omega 7 c$ and/or $15: 0$ iso $2-\mathrm{OH}$. 
Table 2. Genotypic, phenotypic and nutritional characteristics that distinguish strain Dant $3-8^{\top}$ from other Comamonas species

Strains: 1, Dant 3-8 $8^{\mathrm{T}}$ (C. odontotermitis sp. nov.); 2, C. koreensis DSM $18232^{\mathrm{T}} ; 3$, C. testosteroni DSM 50244 ${ }^{\mathrm{T}}$; 4, C. terrigena LMG $1253^{\mathrm{T}}$; 5 , C. denitrificans DSM $17887^{\mathrm{T}}$; 6, C. nitrativorans DSM $13191^{\mathrm{T}} ; 7$, C. aquatica LMG $2370^{\mathrm{T}} ; 8$, C. kerstersii LMG $3475^{\mathrm{T}}$; 9 , C. badia DSM $17552^{\mathrm{T}}$. Data for motility and $\mathrm{G}+\mathrm{C}$ content for reference strains were obtained from Chang et al. (2002), Etchebehere et al. (2001), Gumaelius et al. (2001), Tago \& Yokota (2004) and Wauters et al. (2003); the remaining data were obtained in this study. +, Positive; -, negative; R, resistant; S, sensitive; ND, no data available.

\begin{tabular}{|c|c|c|c|c|c|c|c|c|c|}
\hline Characteristic & 1 & 2 & 3 & 4 & 5 & 6 & 7 & 8 & 9 \\
\hline Source & $\begin{array}{c}\text { Termite } \\
\text { gut }\end{array}$ & Wetland & Soil & $\begin{array}{l}\text { Hay-infusion } \\
\text { filtrate }\end{array}$ & $\begin{array}{l}\text { Activated } \\
\text { sludge }\end{array}$ & Sludge & Freshwater & Human & $\begin{array}{c}\text { Activated } \\
\text { sludge }\end{array}$ \\
\hline Motility & + & - & + & + & + & + & + & + & + \\
\hline Nitrite reduction to nitrogen & - & - & - & - & + & - & - & - & - \\
\hline Alkaline phosphatase & + & + & + & + & - & - & - & - & - \\
\hline Acid phosphatase & + & + & + & + & + & + & + & + & - \\
\hline C8 lipase & + & + & + & + & - & + & + & + & + \\
\hline C14 lipase & - & + & - & - & - & - & - & - & - \\
\hline Valine arylamidase & + & + & + & + & + & + & - & + & + \\
\hline Cystine arylamidase & - & - & + & - & - & - & + & - & - \\
\hline \multicolumn{10}{|l|}{ Assimilation of (API 20NE): } \\
\hline D-Gluconate & + & + & + & + & - & - & + & - & + \\
\hline Caprate & - & - & + & - & - & - & - & - & - \\
\hline Adipate & - & + & + & + & - & + & + & + & + \\
\hline Malate & + & + & + & - & - & + & + & + & + \\
\hline Citrate & + & + & + & - & - & - & - & - & + \\
\hline Phenylacetate & + & - & - & - & - & + & - & - & + \\
\hline \multicolumn{10}{|l|}{ Oxidation of (Biolog GN2): } \\
\hline Acetate & + & + & + & - & - & + & + & + & - \\
\hline cis-Aconitate & - & - & - & + & + & + & - & - & - \\
\hline Propionate & + & + & + & + & - & + & + & - & + \\
\hline$\gamma$-Hydroxybutyrate & + & + & - & + & + & - & + & + & + \\
\hline Itaconate & - & - & - & - & - & - & + & + & - \\
\hline D- and L-Serine & - & + & - & - & - & - & - & - & + \\
\hline L-Threonine & + & + & + & - & + & + & - & + & - \\
\hline L-Phenylalanine & + & + & - & - & - & + & - & + & - \\
\hline Hydroxy-L-proline & + & + & - & - & - & - & - & - & - \\
\hline L-Ornithine & + & - & - & - & - & - & - & - & + \\
\hline Glycyl L-aspartate & + & - & + & - & + & - & - & - & + \\
\hline Glycyl L-glutamate & + & + & + & - & - & - & - & - & + \\
\hline$N$-Acetyl-D-galactosamine & - & - & - & - & - & + & - & - & + \\
\hline Tween 40 & + & + & + & - & - & + & - & + & + \\
\hline Tween 80 & + & + & + & - & - & + & + & + & - \\
\hline \multicolumn{10}{|l|}{ Susceptibility to: } \\
\hline Ampicillin & $\mathrm{R}$ & $\mathrm{R}$ & $\mathrm{R}$ & s & s & s & s & $\mathrm{R}$ & $\mathrm{R}$ \\
\hline Gentamicin & s & S & $\mathrm{R}$ & s & s & s & S & s & S \\
\hline Penicillin G & $\mathrm{R}$ & $\mathrm{R}$ & $\mathrm{R}$ & s & s & s & S & s & S \\
\hline Rifampicin & $\mathrm{R}$ & S & S & s & S & S & s & S & $\mathrm{R}$ \\
\hline Streptomycin & s & s & $\mathrm{R}$ & s & S & s & s & s & $\mathrm{R}$ \\
\hline DNA G $+\mathrm{C}$ content $(\mathrm{mol} \%)$ & 61.6 & 66 & $62.5-64.5$ & 64 & 60.8 & ND & 64 & 61 & 66.3 \\
\hline
\end{tabular}

Odontotermes, referring to the isolation of the type strain from the termite $O$. formosanus).

Aerobic, Gram-negative, non-spore-forming, motile and rod-shaped. After $24 \mathrm{~h}$ growth on nutrient agar at $25^{\circ} \mathrm{C}$, the mean cell size is $0.5-1.0 \mu \mathrm{m}$ width and $2.0-2.5 \mu \mathrm{m}$ length.
Optimum growth occurs at $28-35^{\circ} \mathrm{C}, 0-1 \% \mathrm{NaCl}$ and $\mathrm{pH}$ 7.0. In API 20NE tests, shows positive reactions for oxidase (weak), catalase (weak), nitrate reduction and assimilation of gluconate, malate, citrate and phenylacetate and negative reactions for indole production, hydrolysis of aesculin and gelatin, glucose fermentation, arginine 
dihydrolase, urease, $\beta$-galactosidase and assimilation of glucose, arabinose, mannose, maltose, $N$-acetylglucosamine, caprate and adipate. In API 20E tests, positive for acetoin production and negative for the ONPG test, arginine dihydrolase, lysine decarboxylase, ornithine decarboxylase, $\mathrm{H}_{2} \mathrm{~S}$ production, tryptophan deaminase, indole production, gelatinase and acid production from glucose, mannitol, inositol, sorbitol, rhamnose, sucrose, melibiose, amygdalin and arabinose. In API ZYM tests, shows positive enzyme reactions for alkaline phosphatase, C4 esterase, C8 lipase, leucine arylamidase, valine arylamidase, acid phosphatase and naphthol-AS-BI-phosphohydrolase and negative reactions for C14 lipase, cystine arylamidase, trypsin, $\alpha$-chymotrypsin, $\alpha$-galactosidase, $\beta$-glucuronidase, $\alpha$-glucosidase, $\beta$-glucosidase, $\alpha$-mannosidase, $N$-acetyl- $\beta$-glucosaminidase and $\alpha$-fucosidase. The following compounds are oxidized in the Biolog GN2 microtitre test system: glycogen, Tweens 40 and 80 , methyl pyruvate, monomethyl succinate, acetic acid, formic acid, $\alpha$-, $\beta$ - and $\gamma$-hydroxybutyric acids, $\alpha$-ketobutyric acid, $\alpha$-ketoglutaric acid, $\alpha$-ketovaleric acid, DL-lactate, propionic acid, sebacic acid, succinic acid, bromosuccinic acid, succinamic acid, D- and L-alanine, L-alanyl glycine, L-asparagine, L-aspartic acid, L-glutamic acid, glycyl L-aspartic acid, glycyl L-glutamic acid, hydroxy-L-proline, L-leucine, L-ornithine, L-phenylalanine, L-proline, L-pyroglutamic acid and L-threonine. Cannot oxidize $\alpha$-cyclodextrin, dextrin, $\mathrm{N}$-acetyl-D-galactosamine, $\mathrm{N}$-acetyl-D-glucosamine, adonitol, L-arabinose, D-arabitol, D-cellobiose, i-erythritol, D-fructose, L-fucose, D-galactose, gentiobiose, $\alpha$-D-glucose, myo-inositol, $\alpha$-D-lactose, lactulose, maltose, D-mannose, D-melibiose, methyl $\beta$-D-glucoside, D-psicose, D-raffinose, L-rhamnose, D-sorbitol, sucrose, D-trehalose, turanose, xylitol, cis-aconitic acid, D-galactonic acid lactone, D-galacturonic acid, D-glucosaminic acid, $p$-hydroxyphenylacetic acid, itaconic acid, malonic acid, quinic acid, D-saccharic acid, glucuronamide, alaninamide, L-histidine, D- or L-serine, DL-carnitine, $\gamma$-aminobutyric acid, urocanic acid, inosine, uridine, thymidine, phenylethylamine, putrescine, 2-aminoethanol, 2,3-butanediol, glycerol, DL- $\alpha$-glycerol phosphate, $\alpha$-D-glucose 1-phosphate or D-glucose 6-phosphate. Resistant to ampicillin, penicillin G and rifampicin and sensitive to chloramphenicol, gentamicin, kanamycin, nalidixic acid, novobiocin, streptomycin and tetracycline. The major fatty acids are 16:0 (33.6\%), $18: 1 \omega 7 c(16.2 \%)$ and summed feature $3(16: 1 \omega 7 c$ and/or $15: 0$ iso $2-\mathrm{OH} ; 33.9 \%)$. The DNA $\mathrm{G}+\mathrm{C}$ content is $61.6 \mathrm{~mol} \%$.

The type strain Dant $3-8^{\mathrm{T}}\left(=\mathrm{BCRC} 17576^{\mathrm{T}}=\mathrm{LMG} 23579^{\mathrm{T}}\right)$ was isolated from the gut of the termite $O$. formosanus (Shiraki) from southern Taiwan.

\section{References}

Bauer, A. W., Kirby, W. M. M., Sherris, J. C. \& Turck, M. (1966). Antibiotic susceptibility testing by a standardized single disk method. Am J Clin Pathol 45, 493-496.
Chang, Y. H., Han, J. I., Chun, J., Lee, K. C., Rhee, M. S., Kim, Y. B. \& Bae, K. S. (2002). Comamonas koreensis sp. nov., a non-motile species from wetland in Woopo, Korea. Int J Syst Evol Microbiol 52, 377-381.

Chen, W. M., Laevens, S., Lee, T. M., Coenye, T., de Vos, P., Mergeay, M. \& Vandamme, P. (2001). Ralstonia taiwanensis sp. nov., isolated from root nodules of Mimosa species and sputum of a cystic fibrosis patient. Int J Syst Evol Microbiol 51, 1729-1735.

Chung, Y. C., Kobayashi, T., Kanai, H., Akiba, T. \& Kudo, T. (1995). Purification and properties of extracellular amylase from the hyperthermophilic archeon Thermococccus profundus DT5432. Appl Environ Microbiol 61, 1502-1506.

De Vos, P., Kersters, K., Falsen, E., Pot, B., Gillis, M., Segers, P. \& De Ley, J. (1985). Comamonas Davis and Park 1962, gen. nov., nom. rev. emend., and Comamonas terrigena Hugh 1962, sp. nov., nom. rev. Int J Syst Bacteriol 35, 443-453.

Etchebehere, C., Errazquin, M. I., Dabert, P., Moletta, R. \& Muxi, L. (2001). Comamonas nitrativorans sp. nov., a novel denitrifier isolated from a denitrifying reactor treating landfill leachate. Int J Syst Evol Microbiol 51, 977-983.

Ezaki, T., Hashimoto, Y. \& Yabuuchi, E. (1989). Fluorometric DNADNA hybridization in microdilution wells as an alternative to membrane filter hybridization in which radioisotopes are used to determine genetic relatedness among bacterial strains. Int $J$ Syst Bacteriol 39, 224-229.

Gumaelius, L., Magnusson, G., Pettersson, B. \& Dalhammar, G. (2001). Comamonas denitrificans sp. nov., an efficient denitrifying bacterium isolated from activated sludge. Int J Syst Evol Microbiol 51, 999-1006.

Hall, T. A. (1999). BioEdit: a user-friendly biological sequence alignment editor and analysis program for Windows 95/98/NT. Nucleic Acids Symp Ser 41, 95-98.

Jukes, T. H. \& Cantor, C. R. (1969). Evolution of protein molecules. In Mammalian Protein Metabolism, vol. 3, pp. 21-132. Edited by H. N. Munro. New York: Academic Press.

Kluge, A. G. \& Farris, F. S. (1969). Quantitative phyletics and the evolution of anurans. Syst Zool 18, 1-12.

Mesbah, M., Premachandran, U. \& Whitman, W. B. (1989). Precise measurement of the $\mathrm{G}+\mathrm{C}$ content of deoxyribonucleic acid by highperformance liquid chromatography. Int J Syst Bacteriol 39, 159-167.

Pot, B., Vandamme, P. \& Kersters, K. (1994). Analysis of electrophoretic whole-organism protein fingerprints. In Modern Microbial Methods (Chemical Methods Prokaryotic Systematics Series), pp. 493521. Edited by M. Goodfellow \& A. G. O'Donnell. Chichester: Wiley.

Saitou, N. \& Nei, M. (1987). The neighbor-joining method: a new method for constructing phylogenetic trees. Mol Biol Evol 4, 406425.

Tago, Y. \& Yokota, A. (2004). Comamonas badia sp. nov., a flocforming bacterium isolated from activated sludge. J Gen Appl Microbiol 50, 243-248.

Wauters, G., De Baere, T., Willems, A., Falsen, E. \& Vaneechoutte, M. (2003). Description of Comamonas aquatica comb. nov. and Comamonas kerstersii sp. nov. for two subgroups of Comamonas terrigena and emended description of Comamonas terrigena. Int J Syst Evol Microbiol 53, 859-862.

Wayne, L. G., Brenner, D. J., Colwell, R. R., Grimont, P. A. D., Kandler, O., Krichevsky, M. I., Moore, L. H., Moore, W. E. C., Murray, R. G. E. \& other authors (1987). International Committee on Systematic Bacteriology. Report of the ad hoc committee on reconciliation of approaches to bacterial systematics. Int $J$ Syst Bacteriol 37, 463-464. 